\title{
Research on the Evaluation Method of Aircraft Virtual Maintenance Training Based on AHP
}

\author{
Song Yunxue \\ College of Aeronautical Engineering \\ Civil Aviation University of China \\ Tianjin, China, 300300
}

\author{
Li Zongbo \\ College of Aeronautical Engineering \\ Civil Aviation University of China \\ Tianjin, China, 300300
}

\begin{abstract}
In this paper, AHP is applied to the evaluation of student maintenance capability in virtual maintenance environment, and the design of evaluation system is achieved. Firstly, the mathematical model of AHP is introduced. And then, according to the index system of maintenance training in aircraft maintenance organizations and the characteristics of the virtual maintenance environment, evaluation index system is given. And evaluation model is created. At last, the design of evaluation system is given. The function of each system module is introduced briefly and the process of the system is given. The evaluation system uses the AHP, the quantitative analysis and qualitative analysis, which can reduce the influence of human factors, to enhance the objective and scientific of decision.
\end{abstract}

Keywords-AHP, Virtual Maintenance, Evaluation System

\section{INTRODUCTION}

With the development of computer simulation technology, the use of virtual maintenance training system in place of physical training in civil aircraft maintenance can significantly reduce the cost of staff training in airlines and repair business. Virtual maintenance training system trains staff through a virtual environment. It can improve the staff's maintenance capability, such as interactive virtual maintenance training system developed by Germany's Eberhard Bluemel and Axel Hintze[1], and general framework VORTEX for virtual training designed by BAE SYSTEMS in England[2]. Most of the papers about virtual maintenance training published in foreign countries give a verification and evaluation to the training method proposed in the text. For example, Christopher James Hamblin's doctoral dissertation studies on training efficiency and change in two different virtual environment[3]. The two different environment are helmet displays and desktop displays. In order to achieve the system purpose, the virtual maintenance system needs an objective evaluation system which can give comprehensive evaluation of the staff's maintenance capability.

In order to evaluate the capability of the staff objectively and fairly, the determination of student's maintenance capability index system, the choice of evaluation method and model establishment is a serious problem. Virtual Maintenance is a complex process of human-computer interaction. We cannot use one kind or several kinds of standard answers to evaluate the trainer's actual maintenance capability. And we need give a comprehensive evaluation of the trainer's various aspects factor. This article proposed comprehensive evaluation method of aircraft virtual maintenance training based on AHP. This method overcomes the inadequacies of previous methods to solve the problem of evaluation and further improve the virtual maintenance training systems.

\section{Mathematical Model of AHP}

AHP is a multi-objective decision analysis, quantitative analysis and qualitative analysis method. In the evaluation process, according to the analysis and research on practical problems, we determine the factors influencing the evaluation objectives, establish AHP model of evaluation goals, and calculate the model. Steps are as follows.

a. Construction of comparison matrix. Comparing the same level of $\mathrm{i}$-element and j-element relative to an element of the previous level, we determine their importance to the target, expressed by aij, All comparative results constitute a comparison matrix. We generally use the 1-9 scale method to establish comparison matrix.

b. Calculates the weight vector under the single criterion. By calculating the maximum eigenvalue of comparison matrix, and its corresponding eigenvector, we get relative important coefficient that each element of each layer is opposite some element of the previous, and perform a consistency test. We use the maximum eigenvalue $\lambda \max$ and the order $\mathrm{n}$ to calculate consistency index ICI.

$$
I_{C I}=\left(\lambda_{\max }-n\right) /(n-1)
$$

In General, the order of the comparison matrix is greater, relationships between elements are more difficult to achieve consistency. T.L.Saaty proposed a method that used the average random consistency index IRI to amend ICI. Consistency criterion of comparison matrix is $\mathrm{ICR}=\mathrm{ICI} /$ IRI . When ICR $<0.1$, the comparison matrix is consistent, otherwise, the comparison matrix is inconsistent, and comparison matrix should be adjusted.

c. Calculate the synthetic weights of each layer to the target layer. Suppose we have already figure out important coefficient vector $\mathrm{w}(\mathrm{k}-1)$ which is nk-1 elements on the $\mathrm{k}-1$ layer relative to the total target. Relative important coefficient vector which is nk elements on the $\mathrm{k}$ layer relative the $\mathrm{j}$ element on the $\mathrm{k}-1$ layer is set as follow.

$$
P_{j}^{(k)}=\left(p_{1 j}^{(k)}, p_{2 j}^{(k)}, \cdots, p_{n_{k} j}^{(k)}\right)^{T}
$$


Relative importance coefficient of element which is not dominated by j-element is set to zero.

$$
P^{(k)}=\left(P_{1}^{(k)}, P_{2}^{(k)}, \cdots, P_{n_{k-1}}^{(k)}\right)
$$

This is the $n k \times n k-1$ matrix. It expresses relative important coefficient that element on the $\mathrm{k}$ layer relative to each element on the k-1 layer. The importance coefficient vector $\mathrm{W}(\mathrm{k})$ which is element on the $\mathrm{k}$ layer relative to the target layer is given.

$$
W^{(k)}=\left(w_{1}^{(k)}, w_{2}^{(k)}, \cdots, w_{n_{k}}^{(k)}\right)^{T}=P^{(k)} W^{(k-1)}
$$

d. Consistency test of hierarchical structure. Consistency test of the total order is carried out layer by layer from top to bottom. If you have obtained a comprehensive index of $\mathrm{j}$ element on k-1 layer, and then obtain comprehensive index of $\mathrm{k}$ layer. When the ICR $<0.1$ on the $\mathrm{k}$ layer, then all judgments of the hierarchical structure above $\mathrm{k}$ layer have the overall consistency.

AHP enables object hierarchical and systematic, and applies to evaluate the non-structure characteristic system as well as the multi-objectives, multi-criteria, and multidecision system. It is particularly suitable to solve the problem difficult to quantitative analysis.

\section{THE APPLICATION OF AHP IN COMPREHENSIVE Evaluation of STUDENT MAINTENANCE CAPABILITY IN VIRTUAL ENVIRONMENT}

Virtual Maintenance is a complex process of humancomputer interaction. It needs to reference actual maintenance training examination mechanism of aircraft maintenance organizations and the characteristics of virtual maintenance system. And then we use multiple indexes to comprehensively evaluate maintenance capability of trainees. Comprehensive evaluation steps of student maintenance capability based on AHP in virtual environment are as follow. First, we establish evaluation index system of virtual maintenance training, then establish evaluation system of hierarchical structure model, and then establish the standard value of index, and calculate the index weight. Finally, we determine score of last stage index, and calculate the total score, and then give evaluation results.

\section{A. Establishment of evaluation index system}

In order to evaluate multi-level, multi-factor problem, we must construct a reasonable evaluation index system, and make a lot of mutual associations and mutual restriction factors structured and hierarchical. The selection and establishment of index system is an important foundation and guarantee of comprehensive evaluation.

Virtual maintenance of civil aircraft can simulate the maintenance process, so that trainees can receive the actual maintenance experience. After a failure of the civil aircraft, maintenance personnel analyze the symptoms, use their maintenance experience and search manual, then locate the fault accurately. Then they select the appropriate maintenance tools and use proper troubleshooting method to solve the problem.

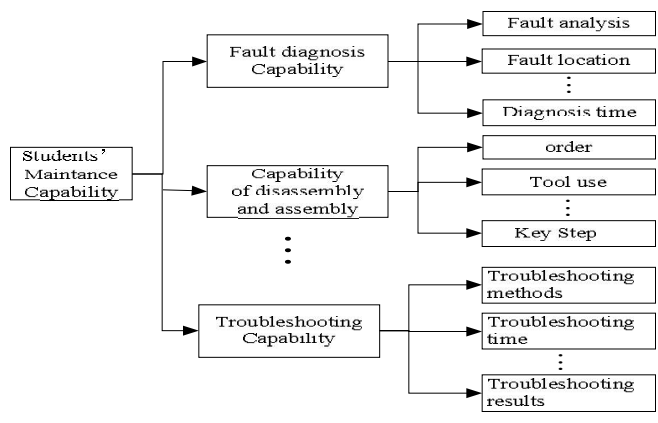

Figure 1. Evaluation index system

According to actual maintenance training and characteristics of virtual maintenance, this article gives an evaluation of student's maintenance capability from aircraft fault diagnosis, capability of 3D body structure assembly and disassembly and troubleshooting capability and so on. We establish index system of student's maintenance capability. Index system is shown in figure 1.

\section{B. Calculation of index weight and total score}

According to the hierarchical structure model, we establish each index weight distribution table and give a table of index weight distribution as the demonstration. As table I.We calculate the maximum eigenvalue according to a weight vector in table one. Then we obtain consistency index $\mathrm{CI}=0.074$. According to average random consistency index, we get $\mathrm{CR}=0.066<0.1$. It has satisfactory consistency. Otherwise we must adjust the matrix until consistency is met. According to each index weight distribution, we set score of the index on the final layer, and then get evaluation total score.

TABLE I. INDEX WIGHT DISTRIBUTION TABLE

\begin{tabular}{|c|c|c|c|c|c|}
\hline Index & Order & Tool & Time & $\begin{array}{c}\text { Key St } \\
\text { ep }\end{array}$ & $\begin{array}{c}\text { Right Step } \\
\text { Rate }\end{array}$ \\
\hline Order & 1 & 4 & 2 & 0.33 & 3 \\
\hline Tool & 0.25 & 1 & 2 & 0.2 & 2 \\
\hline Time & 0.5 & 0.5 & 1 & 0.2 & 0.5 \\
\hline Key Step & 3 & 5 & 5 & 1 & 5 \\
\hline $\begin{array}{c}\text { Right Step } \\
\text { Rate }\end{array}$ & 0.33 & 0.5 & 2 & 0.2 & 1 \\
\hline Wight & 0.232 & 0.117 & 0.075 & 0.483 & 0.093 \\
\hline
\end{tabular}

\section{DESIGN AND IMPLEMENTATION OF ViRTUAL MaInTENANCE EVALUATION System}

This system uses VC++ 6.0, ACCESS database and DLL technology. The evaluation system produces a DLL file. We use the DLL file as a module of virtual maintenance training system. And in this way we can easily maintenance this system. Function modules in this evaluation system are given in figure 2. 


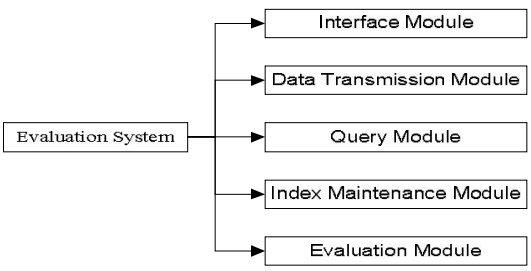

Figure 2. Functional modules diagram of evaluation system

\section{A. Main function modules}

(1) Interface module. It provides an interface that the evaluation system can be called by virtual maintenance training system. And it gives a standard to the interface.

(2) Data transmission module. It is responsible for the connection between each module and database and data transmission. It can get maintenance operating data from virtual environment. It provides data storage, and data transfer between the modules.

(3) Query Module. You can query the results of the evaluation. Students can query the results of their maintenance operation and teachers can query all results. According to different query condition, you can query more accurately. It also provides fuzzy query.

(4) Index maintenance module. It can dynamically create and edit evaluation index system of the object in real time. According to the different demand, you can make different setting of index system, and then edit the standard of index. According to hierarchical relationships and index attribute of the index system, index system is stored in the database in the form of tree structure and node attributes. It can add, modify, and delete index in real time.

(5) Evaluation module. The module calculates index weight with evaluation model and test the consistency. Evaluators simply follow the dialog box to calculate weight. Users can view the CI, RI values. Comprehensive score of the end index and the index weight, the module gives the results of evaluation.

\section{B. The evaluation system running processes}

Comprehensive evaluation system gets student's maintenance operation data from the virtual maintenance system. The system completes the evaluation of student maintenance capability through mutual cooperation between the modules, as in figure 3 . The general process is as follows. Enter the evaluation system, first of all, the user sets the index and saves set of index according to the evaluation needs. And second this system uses this mathematical model of AHP to calculate index weight. Then the system gets student's maintenance operation data from virtual environment and gives a score of the end index to student's operation according to the standard. Finally, the system gives comprehensive evaluation through the weight of each index, and saves the result into database for query.

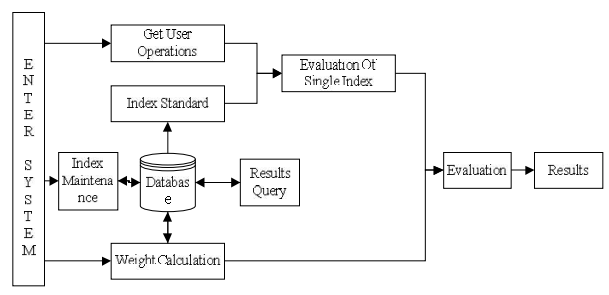

Figure 3. Evaluation system flow chart

\section{C. . Example of maintenance evaluation}

Students practice in virtual environment. The virtual environment is as figure 4 . And the fault is set by the teacher. The system records maintenance data of the student. After the test, the system uses index system to evaluate the student's capability. And it gives score. The evaluation application interface is as in figure 5 .

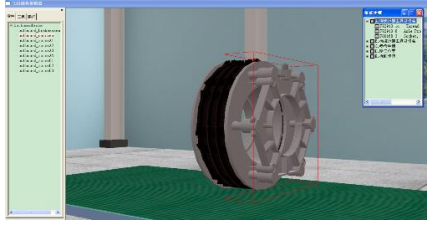

Figure 4. Environment of aircraft virtual maintenance training system

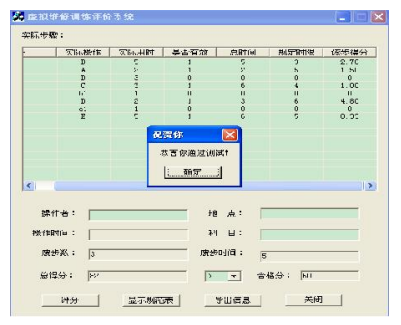

Figure 5. Interface of evaluation result

\section{CONCLUSION}

Evaluation of virtual maintenance training for civil aircraft is a complex task. The capability of students should be comprehensive, scientifically and objectively quantified. It is very import to success that every index must be feasible and scientific. The article gives the main index of maintenance evaluation with the civil aviation actual maintenance. This article uses AHP. It can be simple, objective and comprehensive, scientifically accurate, and more fully to reflect the comprehensive level of the student's civil aircraft maintenance capability.

\section{REFERENCES}

[1] Eberhard Bluemel; Axel Hintx; Torsten Schulz; Marco Scbumann; Stefan Stuering. Virtual Environment for the Training of Maintenance And Service Tasks [J]. Proceedings of the 2003 Winter Simulation Conference.2003, PP:2001-2007.

[2] Stephanie Gerbaud; Nicolas Mollet; Franck Ganier; Bruno Arnaldi. J.T.GVT: a platform to create virtual environments for procedural training [J]. IEEE Virtual Reality 2008, Reno, Nevada, USA.2008, PP:225-232.

[3] Hamblin,C.J. TRANSFER OF TRAINING FROM VIRTUAL REALITY ENVIRONMENTS, Wichita State University. 
[4] THOMAS L SAATY. Decision making - the analytic hierarchy and net2 work processes (AHP/ANP) [J]. Journal Of Systems Science And Systems Engineering. 2004 (3), PP:1-35.

[5] Saaty T L. Highlights and critical points in the theory and application of analytic hierarchy process [J]. European Journal of Operational Research, 1997, 74: 426-447.

[6] WANG Wen-yun; TANG Jin-guo; SUN Yuan. Development of Missile Techno-Preparing Interactive Training System [J]. Journal of System Simulation,2008,20(S):161-164.
[7] LIU Jing; WANG De-gong; CHANG Shuo. Equipment Maintain System Efficiency Analysis based on AHP [J]. Equipment Manufactring Technology,2009,(5):130-134.

[8] CHANG Jia-ne; JIANG Tai-li. Research on the Weight of Coefficient through Analytic Hierarchy Process [J].Journal of Wuhan University of Technology(Information \& Management Engineering), 2007, 29(1): $1-4$.

[9] GUO Peng; ZHENG Wei-wei. Certain Improvements in Application of AHP [J].Systems Engineering.1995,(1):28-31. 